Article

\title{
Water Diffusion Modulates the CEST Effect on Tb(III)-Mesoporous Silica Probes
}

\author{
Fabio Carniato ${ }^{1, *(\mathbb{D})}$, Giuseppe Ferrauto ${ }^{2}$, Mónica Muñoz-Úbeda ${ }^{1}(\mathbb{C})$ and Lorenzo Tei ${ }^{1}$ \\ 1 Department of Science and Innovation Technology, University of Eastern Piedmont, Via T. Michel 11, \\ 15121 Alessandria, Italy; monicamubeda@gmail.com (M.M.-Ú.); lorenzo.tei@uniupo.it (L.T.) \\ 2 Department of Molecular Biotechnology and Health Sciences, University of Torino, Via Nizza 52, \\ 10126 Torino, Italy; giuseppe.ferrauto@unito.it \\ * Correspondence: fabio.carniato@uniupo.it
}

Received: 22 July 2020; Accepted: 26 August 2020; Published: 1 September 2020

\begin{abstract}
The anchoring of lanthanide(III) chelates on the surface of mesoporous silica nanoparticles (MSNs) allowed their investigation as magnetic resonance imaging (MRI) and chemical exchange saturation transfer (CEST) contrast agents. Since their efficiency is strongly related to the interaction occurring between Ln-chelates and "bulk" water, an estimation of the water diffusion inside MSNs channels is very relevant. Herein, a method based on the exploitation of the CEST properties of TbDO3A-MSNs was applied to evaluate the effect of water diffusion inside MSN channels. Two MSNs, namely MCM-41 and SBA-15, with different pores size distributions were functionalized with TbDO3A-like chelates and polyethylene glycol (PEG) molecules and characterized by HR-TEM microscopy, IR spectroscopy, $\mathrm{N}_{2}$ physisorption, and thermogravimetric analysis (TGA). The different distribution of $\mathrm{Tb}$-complexes in the two systems, mainly on the external surface in case of MCM-41 or inside the internal pores for SBA-15, resulted in variable CEST efficiency. Since water molecules diffuse slowly inside silica channels, the CEST effect of the LnDO3A-SBA-15 system was found to be one order of magnitude lower than in the case of TbDO3A-MCM-41. The latter system reaches an excellent sensitivity of ca. $55 \pm 5 \mu \mathrm{M}$, which is useful for future theranostic or imaging applications.
\end{abstract}

Keywords: chemical exchange saturation transfer; contrast agents; lanthanide complexes; magnetic resonance imaging; mesoporous silica nanoparticles; PARACEST agents; water diffusion

\section{Introduction}

The distinctive properties of mesoporous silica nanoparticles (MSNs) in terms of their tunable mesoporosity, high thermal stability, chemical versatility, and good biocompatibility, have come to receive increasing attention by the scientific community [1,2]. In particular, the use of mesoporous silica for the preparation of novel diagnostic and biomedical probes has seen an exponential growth of literature reports in the last decade [2-5]. Among the possible applications, the magnetic resonance imaging (MRI) and theranostic fields have taken advantage of the presence of empty channels and high specific surface areas for the development of efficient and more sensitive MRI contrast or theranostic agents [6-10].

On the other hand, in 2000, Balaban et al. [11] reported for the first time the feasibility to generate contrast in MR images through the application of CEST probes [12-14]. In the last decade, a number of molecules have been investigated as possible CEST agents. In particular, both diamagnetic (e.g., polysaccarides, peptides, etc.) $[12,15,16]$ and paramagnetic (Ln-based PARACEST complexes) $[12,13,17-19]$ have been described as efficient for in vitro and in vivo contrast generation and as responsive MRI probes [20-24]. The peculiarity of such agents is that they generate a frequency-encoded contrast, thus the contrast arises only if the proper radiofrequency pulse is applied. 
In such a way, the resonance of the CEST proton pool is directly saturated and, simultaneously, the "bulk" water protons resonance is partially saturated (via chemical exchange of spins), thus generating contrast. The most important drawback of such agents, which strongly hampers the in vivo translation, is the low sensitivity. In order to overcome this drawback, nano- and micro-sized systems [22,25-29] have been devised to increase the number of mobile protons available and therefore to improve the sensitivity threshold of the agent. In this context, we have already reported the functionalization of MCM-41 MSNs with LnDO3A chelates $(\mathrm{Ln}=\mathrm{Eu}, \mathrm{Tm}, \mathrm{Tb}, \mathrm{Gd}, \mathrm{DO} 3 \mathrm{~A}=1,4,7,10$-tetraazacyclododecane-1,4,7-triacetic acid), and investigated as CEST agents by exploiting the dipolar interaction with proximate $\mathrm{OH}$ groups exposed on the silica surface [25]. TbDO3A was the most efficient among the explored LnDO3A chelates showing a larger shift and excellent sensitivity down to the $\mu \mathrm{M}$ range [25].

From previous studies on Gd-based MSNs, we have demonstrated that the final performance of the conjugated mesoporous systems is strictly related to the distribution of the Gd-chelate on the silica surface or into the pores as well as to the type of interactions occurring between the silica surface and the Gd-complex [30,31]. In particular, two hybrid materials based on MSNs with different pores size distribution, SBA-15 and MCM-41, and functionalized with GdDOTA-like complexes (DOTA = 1,4,7,10-tetraazacyclododecane-1,4,7,10-tetraacetic acid) have been employed to show the different relaxometric behavior as a function of the Gd-chelate distribution [30]. In fact, the Gd(III)-complexes were mainly distributed into the channels of SBA-15 (characterized by the presence of large pores of $8.5 \mathrm{~nm}$ ) and on the external surface of MCM-41 (characterized by an architecture with small pores of $2.5 \mathrm{~nm}$ ). From a relaxometric point of view, Gd-functionalized MCM-41 and SBA-15 showed a markedly different relaxivity $\left(27\right.$ and $7 \mathrm{mM}^{-1} \mathrm{~s}^{-1}$, respectively at $20 \mathrm{MHz}$ and $310 \mathrm{~K})$ [30]. This divergence was ascribed to the presence into the pores of SBA-15 of a large fraction (ca. $80 \%$ ) of Gd(III)-complexes that was unable to have access to water molecules freely diffusing with the bulk. This hindered or limited access of the water molecules to the Gd(III)-complex inside the pores prevented the expected relaxivity increase [30]. A similar study was also carried out by J. J. Davis and colleagues who investigated how the localization of conjugated GdDOTAMA chelates on the silica surface influenced the relaxation properties of the final samples [32]. The best relaxometric performances were achieved when the complexes are linked in proximity of the pores entrance.

Noteworthy, the slow translational and rotational dynamics of water molecules in MCM-41-S and MCM-48-S mesoporous silicas was also demonstrated using the incoherent quasielastic neutron scattering technique [33].

With the aim to further investigate the problem of water diffusion into MSNs pores, we considered that also the CEST effect is controlled by the water exchange and diffusion processes. Therefore, probes containing $\mathrm{Ln}(\mathrm{III})$-chelates delocalized in different domains of MSNs (inside the pores or on the external surface) could have completely different MRI efficiency and could be used to qualitatively evaluate the water diffusion and accessibility to the paramagnetic sites.

In this context, two CEST probes were prepared by anchoring TbDO3A-like chelates to the surface of MCM-41 and SBA-15 and further functionalized with polyethylene glycol (PEG5000) molecules in order to improve the stability of the water suspensions. The physico-chemical properties of the silica particles before and after functionalization were determined by high-resolution transmission electron microscopy (TEM), IR spectroscopy, $\mathrm{N}_{2}$ physisorption, and thermogravimetric analysis, and their CEST properties were evaluated in detail.

\section{Materials and Methods}

All chemicals were purchased from Sigma-Aldrich Co. LLC and used without further purification.

\subsection{Synthesis of the Functionalized Tb(III)-DO3A Complex}

The synthesis of the DO3A-hexanoic acid was carried out following the procedure reported in the literature $[25,34]$. The $\mathrm{Tb}(\mathrm{III})$ complex was prepared by slow addition of $\mathrm{TbCl}_{3}$ to a solution of the ligand in water at $\mathrm{pH}$ 6. The mixture was stirred overnight at room temperature and $\mathrm{pH} 6.5$. 
Then, the $\mathrm{pH}$ was raised to 8.5 and the mixture was stirred for $2 \mathrm{~h}$. Centrifugation at 10,000 rpm for $5 \mathrm{~min}$ at $298 \mathrm{~K}$ allowed the separation of $\mathrm{Tb}(\mathrm{OH})_{3}$ from the solution. Finally, the solvent was removed under reduced pressure leading to the formation of the desired product as a powder. ESI-MS: $\mathrm{m} / \mathrm{z}$ calc. for $\mathrm{Tb}$ (III)-DO3A $\left(\mathrm{C}_{20} \mathrm{H}_{33} \mathrm{TbN}_{4} \mathrm{O}_{8}\right): 616.4 \mathrm{~g} / \mathrm{mol}$; found $615.2 \mathrm{~g} / \mathrm{mol}$ [M-]. The peaks related to $\mathrm{Tb}$ (III) complexes show the correct isotopic distribution.

\subsection{Synthesis and Functionalization of the Mesoporous Silica Supports}

MCM-41 was purchased from Sigma-Aldrich Co. LLC.

SBA-15 was prepared following a procedure reported in the literature [35]. In detail, $4.0 \mathrm{~g}$ of Pluronic $\mathrm{P} 123$ were dissolved in $30 \mathrm{~mL}$ of water and $120 \mathrm{~mL}$ of $\mathrm{HCl} 2 \mathrm{~N}$ with stirring at $308 \mathrm{~K}$. Then, $8.5 \mathrm{~g}$ of TEOS were added to the solution and stirred at $308 \mathrm{~K}$ for $24 \mathrm{~h}$. The mixture was aged at $373 \mathrm{~K}$ in autoclave for $24 \mathrm{~h}$. The solid product was filtered and washed several times with $\mathrm{H}_{2} \mathrm{O}$. The calcination of the solid was carried out increasing the temperature at $1 \mathrm{~K} / \mathrm{min}$ under air flow from room temperature to $823 \mathrm{~K}$ and heating the material at $823 \mathrm{~K}$ for $5 \mathrm{~h}$.

$\mathrm{NH}_{2} / \mathrm{MCM}-41$ and $\mathrm{NH}_{2} / \mathrm{SBA}-15$ : the calcined MCM-41 (1.0 g) and SBA-15 (1.0 g) samples were firstly treated under vacuum at $250{ }^{\circ} \mathrm{C}$ for $2 \mathrm{~h}$ to activate the surface. Then, the materials were suspended in toluene $(100 \mathrm{~mL})$ under $\mathrm{N}_{2}$ and 3-aminopropyltriethoxysilane (40 wt \%) was added. The mixtures were stirred at $323 \mathrm{~K}$ for $20 \mathrm{~h}$. The suspension was then filtered, and the products washed with diethyl ether to remove the unreacted silane. Finally, the samples were dried at $333 \mathrm{~K}$ for $2 \mathrm{~h}$.

\subsection{Anchoring of Tb(III)-DO3A Complexes and PEG5000-COOH to the Organo-Modified MSNs}

$\mathrm{NH}_{2} / \mathrm{MCM}-41$ (300 mg) and $\mathrm{NH}_{2} / \mathrm{SBA}-15$ (300 mg) were suspended in DMF (20 mL) for $30 \mathrm{~min}$. In parallel, the $\mathrm{Tb}(\mathrm{III})$ complex $(260 \mathrm{mg})$ containing a free carboxylic acid was dissolved in DMF $(30 \mathrm{~mL})$ and activated by adding one molar equivalent of HATU and DIPEA. The solutions of the activated complexes were added to the suspensions of $\mathrm{NH}_{2} / \mathrm{MCM}-41$ and $\mathrm{NH}_{2} / \mathrm{SBA}-15$ and stirred at $323 \mathrm{~K}$ for $24 \mathrm{~h}$. The suspensions were then filtered, and the solids were washed several times with $\mathrm{H}_{2} \mathrm{O}$ to remove the unreacted complex. Both the solids were functionalized with PEG molecules. In detail, $210 \mathrm{mg}$ of TbDO3A-MCM-41 and TbDO3A-SBA-15 were suspended in $10 \mathrm{~mL}$ of water. In parallel, $50 \mathrm{mg}$ of PEG5000-COOH were dissolved in $10 \mathrm{~mL}$ of water in the presence of $19.2 \mathrm{mg}$ of EDC and $46.3 \mathrm{mg}$ of Sulfo-NHS. The solution was added to the previous suspensions and stirred at $298 \mathrm{~K}$ for $20 \mathrm{~h}$. Finally, the suspensions were filtered and the powders were washed with water $(20 \mathrm{~mL})$ in order to remove the unreacted PEG molecules and dried at $323 \mathrm{~K}$ for $4 \mathrm{~h}$.

\subsection{Characterization of Materials}

The amount of $\mathrm{Tb}(\mathrm{III})$ in the final hybrid material was measured by ICP-MS technique. The elemental analyses were performed with a Thermo Scientific (Waltham, MA, USA) X5 series inductively coupled plasma mass spectrometer. Prior to the analysis, the samples were mineralized by dissolution in 1:1 $\mathrm{HNO}_{3} / \mathrm{HF}$ at $373 \mathrm{~K}$ for $24 \mathrm{~h}$.

Electrospray ionization mass spectra (ESI MS) were recorded on an SQD 3100 mass detector (Waters), operating in positive or negative ion mode, with $1 \% v / v$ formic acid in methanol as the carrier solvent.

HRTEM images were collected on a JEOL 3010 high resolution transmission electron microscope operating at $300 \mathrm{kV}$. Specimens were prepared by dispersing the samples by sonication in isopropanol and by depositing few drops of the suspensions on carbon-coated grids.

Infrared (IR) spectra were recorded under vacuum conditions in the range $4000-400 \mathrm{~cm}^{-1}$ at $4 \mathrm{~cm}^{-1}$ resolution using a Bruker Equinox 55 spectrometer.

$\mathrm{N}_{2}$ physisorption measurements were carried out at $77 \mathrm{~K}$ in the relative pressure range from $1 \times 10^{-6}$ to $1 \mathrm{P} / \mathrm{P}_{0}$ by using a Quantachrome Autosorb $1 \mathrm{MP} / \mathrm{TCD}$ instrument. Prior to the analysis, the samples were out gassed at $373 \mathrm{~K}$ for $3 \mathrm{~h}$ (residual pressure lower than $10^{-6}$ torr). Apparent surface areas were determined by using the BET equation, in the relative pressure range from 0.01 to $0.1 \mathrm{P} / \mathrm{P}_{0}$. 
Pore volume and diameter were defined by the Barret-Joyner-Halenda (BJH) approach (applied to the desorption branch) for MCM-41 derivative samples and by NLDFT method for SBA-15 and functionalized systems.

Thermogravimetric analyses (TGA/DTG) of materials were performed under an oxygen flow $\left(100 \mathrm{~mL} \mathrm{~min}^{-1}\right)$ with a SETSYS Evolution TGADTA/DSC thermobalance, heating from 323 to $1073 \mathrm{~K}$ at $10 \mathrm{~K} \mathrm{~min}^{-1}$.

Dynamic light scattering (DLS) measurements were performed by using a Zetasizer NanoZS at $298 \mathrm{~K}$ (Malvern Instruments; Malvern, UK) operating in a particle size range from $0.6 \mathrm{~nm}$ to $6 \mu \mathrm{m}$, equipped with a He-Ne laser with $\lambda=633 \mathrm{~nm}$. Before the analysis, the samples were dispersed in PBS solution $(20 \mathrm{mg} / \mathrm{mL})$.

\subsection{CEST Experiments}

For CEST experiments, TbDO3A-MCM-41 and TbDO3A-SBA-15 MSNs were suspended in water at the concentration of $20 \mathrm{mg} / \mathrm{mL}$ and added with xanthan gum $(2 \mathrm{mg} / \mathrm{mL})$ to stabilize the suspension. In order to avoid silica aggregation, they were sonicated for $45 \mathrm{~min}, 59 \mathrm{~Hz}$, power $80 \%, 313 \mathrm{~K}$ in an ultrasonic bath. Samples of $\mathrm{Tb}(\mathrm{III})-\mathrm{MSN}$ at variable concentration or $\mathrm{pH}$ were prepared for MRI acquisitions.

\subsection{MRI Acquisitions and Image Analysis}

Z-spectra were acquired at 7.1 $\mathrm{T}$ on a Bruker Avance 300 spectrometer equipped with a microimaging probe. A frequency-offset range of $\pm 150 \mathrm{ppm}$ was investigated. A typical RARE spin-echo sequence (RARE factor varying from 4 to 32 depending on the $T_{2}$ of the sample) with an echo time of $3 \mathrm{~ms}$ and a TR value of $5 \mathrm{~s}$ was used. An isotropic $64 \times 64$ acquisition matrix with a FOV of $30 \mathrm{~mm}$ and a slice thickness of $1 \mathrm{~mm}$ were used. The whole sequence was preceded by a saturation scheme consisting of a continuous rectangular wave pulse $2 \mathrm{~s}$ with a proper radiofrequency $\mathrm{B}_{1}$. The Z-spectra were interpolated by smoothing splines to identify the zero-offset on a pixel-by-pixel basis of the bulk water and, then, to assess the correct $S T \%$ value over the entire range of frequency offsets investigated [36]. Custom-made software, compiled in the Matlab platform (Mathworks Inc., Natick, MA, USA), was used. CEST effect is calculated by using the following formula:

$$
S T \%=\left(1-\frac{M_{S}}{M_{0}}\right) \times 100
$$

where $M_{S}$ is the intensity of the bulk water NMR signal after the irradiation on resonance $(\Delta \omega)$ of the mobile proton pool and $M_{0}$ is the intensity of the bulk water NMR signal after the irradiation at $-\Delta \omega$.

$T_{2 \mathrm{w}}$ images were acquired by using a standard $T_{2 \mathrm{w}}$ RARE sequence with the following parameters $(\mathrm{TR}=5000 \mathrm{~ms}, \mathrm{TE}=5.5 \mathrm{~s}, \mathrm{FOV}=1 \mathrm{~cm} \times 1 \mathrm{~cm}$, slice thickness $=1 \mathrm{~mm}$, RARE factor $=4-32$ depending on the $T_{2}$ of the sample). $T_{2}$ values were measured by using a MSME sequence (TR $=2000 \mathrm{~ms}, 10$ variable TE ranging from 11 to $500 \mathrm{~ms}, \mathrm{FOV}=1 \mathrm{~cm} \times 1 \mathrm{~cm}$, slice thickness $=1 \mathrm{~mm}$ ).

\section{Results}

MCM-41 and SBA-15 MSNs with particle sizes in the 100-200 nm and 500-600 nm range characterized by an order array of hexagonal channels (qualitatively evaluated by TEM images at low (Supplementary Figure S1) and high magnifications (Figure 1) were functionalized with amino groups, following a post-synthesis approach optimized in our lab and reported in the literature $[30,31]$. 

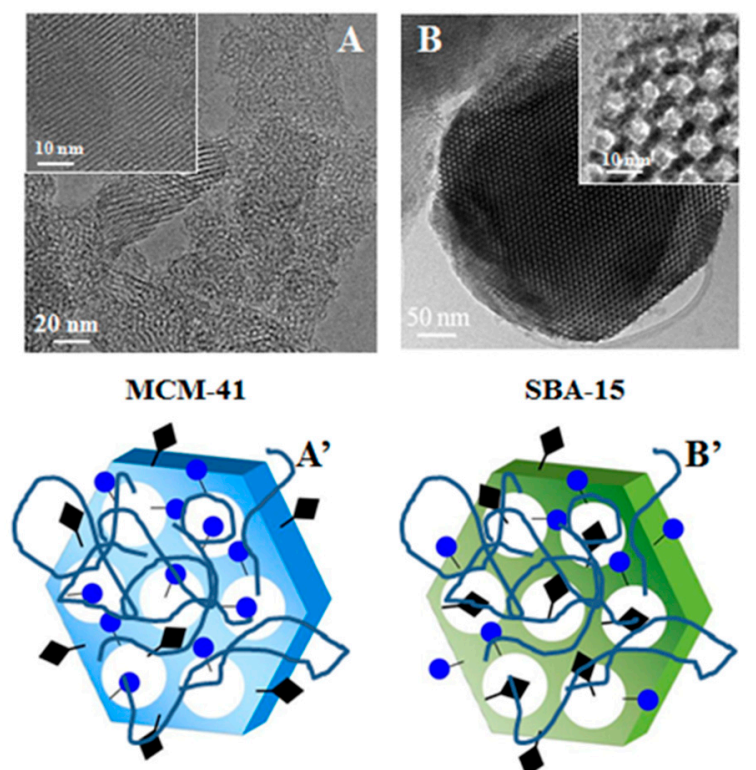

SBA-15
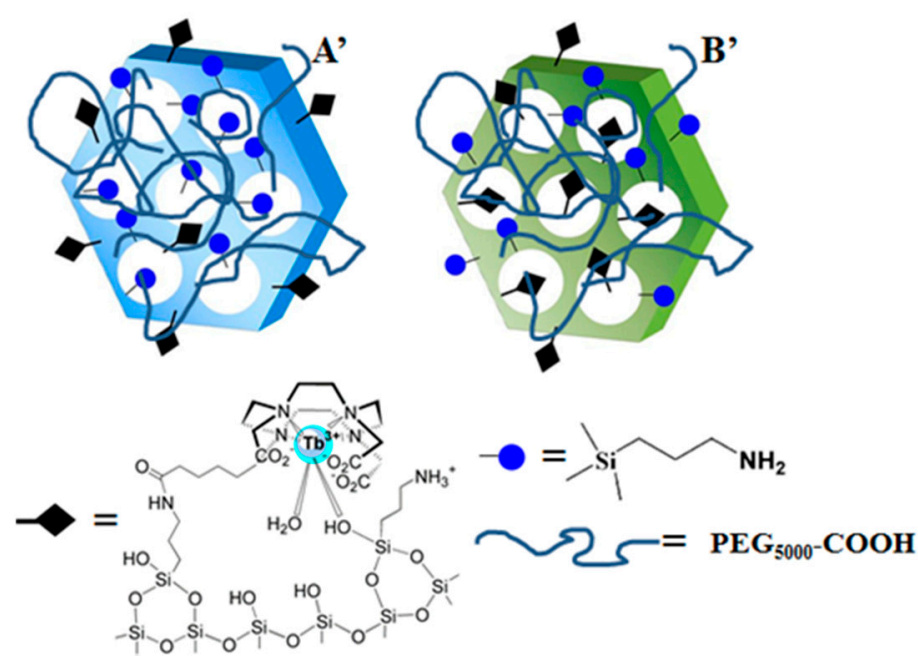

Figure 1. TEM micrographs of MCM-41 (A) and SBA-15 (B). A schematic view of the distribution of Tb-DO3A chelates on the surface of MCM-14 and SBA-15 is reported in $\mathrm{A}^{\prime}$ and $\mathrm{B}^{\prime}$, respectively. The scheme of the interaction between TbDO3A-like chelates and the surface of the organo-modified MSN was assumed after previous studies on similar systems (Reproduced from [25] with permission from The Royal Society of Chemistry).

The neutral $\mathrm{Tb}(\mathrm{III})$-DO3A complex bearing a hexanoic acid pendant group (Scheme 1) was covalently linked to part of the amino groups exposed on the surface by amide coupling using $\mathrm{O}-\left(7\right.$-azabenzotriazol-1-yl)-N, $\mathrm{N}, \mathrm{N}^{\prime}, \mathrm{N}^{\prime}$-tetramethyluronium hexafluorophosphate (HATU) as an acid activator and $\mathrm{N}, \mathrm{N}$-diisopropyl-ethylamine (DIPEA) as a base, in DMF (Scheme 1). Finally, both TbDO3A-MCM-41 and TbDO3A-SBA-15 were functionalized with polyethylene glycol (PEG5000) in order to improve the stability of their aqueous suspensions. The pegylation was carried out by the reaction of PEG5000-COOH in the presence of 1-Ethyl-3-(3-dimethylaminopropyl)carbodiimide (EDC) and Hydroxy-2,5-dioxopyrrolidine-3-sulfonic acid sodium salt (Sulfo-NHS) activators.

The functionalization reactions were monitored by infrared spectroscopy (Figure 2). In particular, the IR spectra of MCM-41 and SBA-15, collected at room temperature under vacuum, showed a typical band at $3745 \mathrm{~cm}^{-1}$ due to the stretching of isolated silanol groups ( $\mathrm{Si}-\mathrm{OH}$ ) and a wide absorption centered at $3500 \mathrm{~cm}^{-1}$ attributed to the Si-OH groups involved in hydrogen bonds [37]. The amount of $\mathrm{OH}$ groups exposed on the silica surface was quantified by thermogravimetric analysis, (323-1273 K) under Argon flow, and resulted to be for MCM-41 and SBA-15, 2.16 and 4.50 per nm², respectively (Supplementary Figure S2). A drastic decrease of these IR absorptions was observed after reaction with aminopropyltriethoxysilane as a consequence of the consumption of the silanol groups (Figure 2A,B). The peaks typical of the amino groups, 3370 and $3300 \mathrm{~cm}^{-1}$ assigned to the asymmetric and symmetric stretching modes and $1595 \mathrm{~cm}^{-1}$ due to the bending of $\mathrm{NH}_{2}$, were observed in both the organo-modified solids. Thermogravimetric analysis allowed estimating the amount of $\mathrm{NH}_{2}$ groups on the MSNs surface as, approximately, 2.0 and $4.0 \mathrm{mmol} \mathrm{g}^{-1}$ for SBA-15 and MCM-41, respectively (Supplementary Figure S3). 


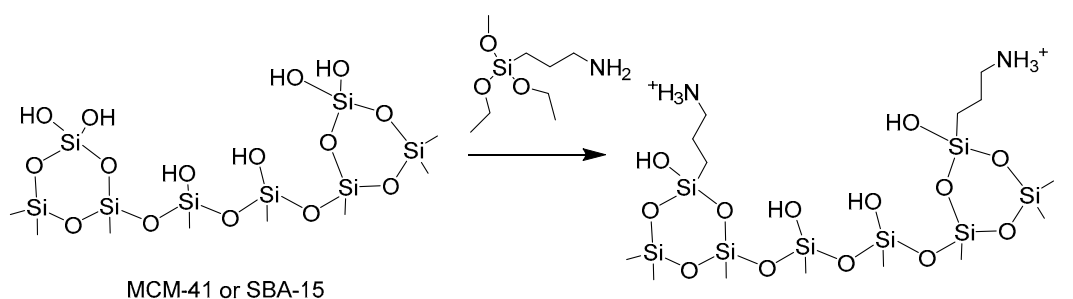

MCM-41 or SBA-15

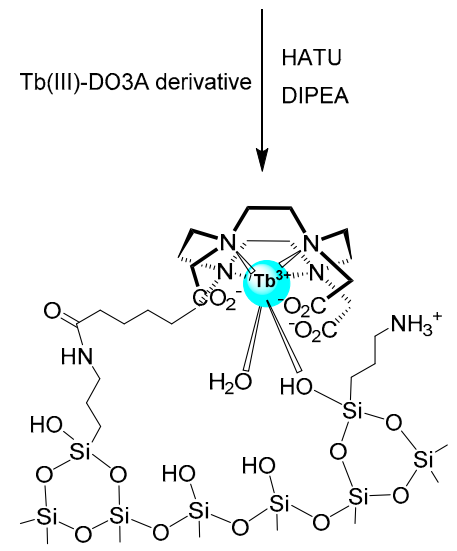

Scheme 1. Schematic view of the functionalization of silica surface with amino groups and $\mathrm{Tb}(\mathrm{III})-\mathrm{DO} \mathrm{A}$ derivative complex.
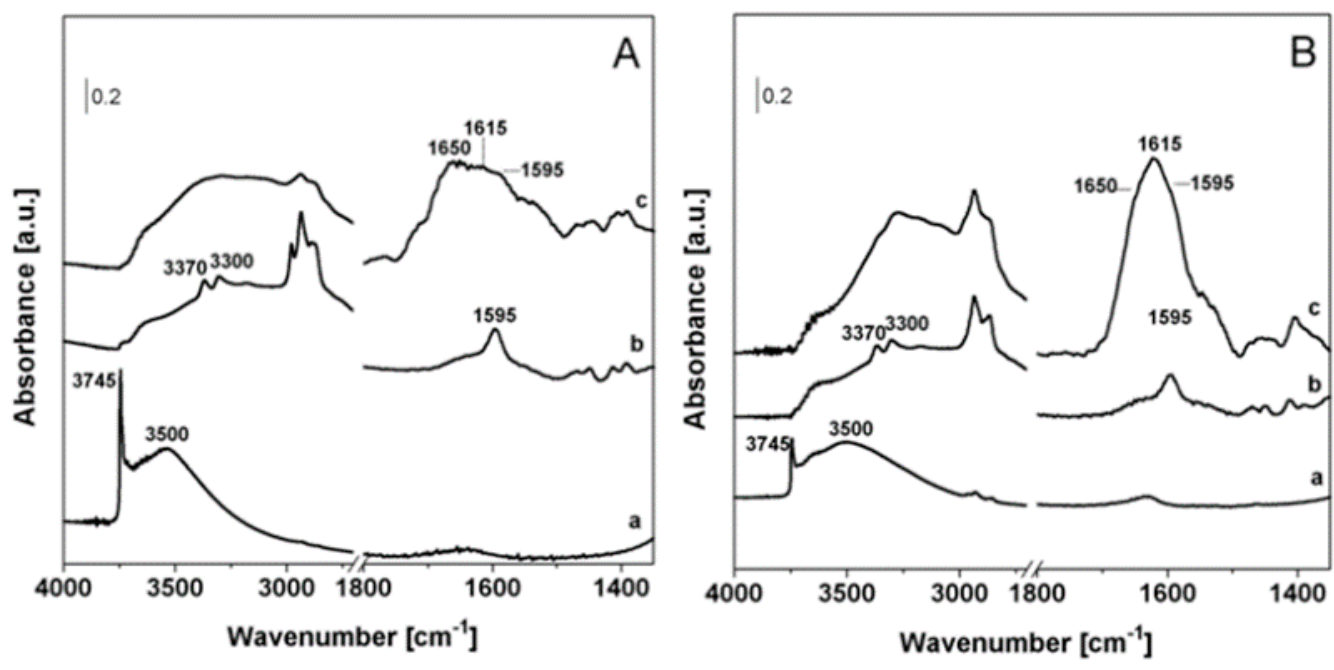

Figure 2. IR spectra, collected at RT and under vacuum of MCM-41 (A, curve a), $\mathrm{NH}_{2}-\mathrm{MCM}-41$ (A, b), TbDO3A-MCM-41 (A, c), SBA-15 (B, a), NH2-SBA-15 (B, b) and TbDO3A-SBA-15 (B, c).

Finally, IR spectra of the materials after both chelate conjugation and pegylation (hereafter named TbDO3A-MCM-41 and TbDO3A-SBA-15) are characterized by the presence of two absorptions: (i) at $1650 \mathrm{~cm}^{-1}$, attributed to the stretching of amide groups formed by the coupling of both $\mathrm{Tb}$ (III)-complexes and PEG to the surface and (ii) at $1615 \mathrm{~cm}^{-1}$ assigned to the stretching modes of $\mathrm{COO}^{-}$units of the $\mathrm{Tb}(\mathrm{III})-\mathrm{DO} 3 \mathrm{~A}$ chelates (Figure 2A,B). The spectra also showed the typical bands of the amino functionalities (i.e., absorption at $1595 \mathrm{~cm}^{-1}$ ), indicating that part of the total amount of $-\mathrm{NH}_{2}$ groups did not participate into the conjugation reaction.

The amount of $\mathrm{Tb}$ in the final materials was measured by inductively coupled plasma mass spectrometry (ICP-MS) and resulted to be 0.08 and $0.23 \mathrm{mmol} \mathrm{g}^{-1}$ for TbDO3A-MCM-41 and TbDO3A-SBA-15, respectively. 
The distribution of the $\mathrm{Tb}(\mathrm{III})$-chelates in the two organo-modified silica was evaluated by $\mathrm{N}_{2}$ physisorption analysis at $77 \mathrm{~K}$. MCM-41, NH $2-M C M-41$ and TbDO3A-MCM-41 showed a type "IV" isotherm (IUPAC classification) with an "H2" hysteresis loop (Supplementary Figure S4) [38]. MCM-41 showed a specific surface area (SSA) (estimated by Brunauer-Emmett-Teller, BET method) of $905 \mathrm{~m}^{2}$ $\mathrm{g}^{-1}$ and a pore diameter of $2.8 \mathrm{~nm}$ (see Figure 3 and Table 1). The anchoring of $\mathrm{NH}_{2}$ groups led to a reduction of both the volume and diameter of pores of about $25 \%$ and $15 \%$, respectively.
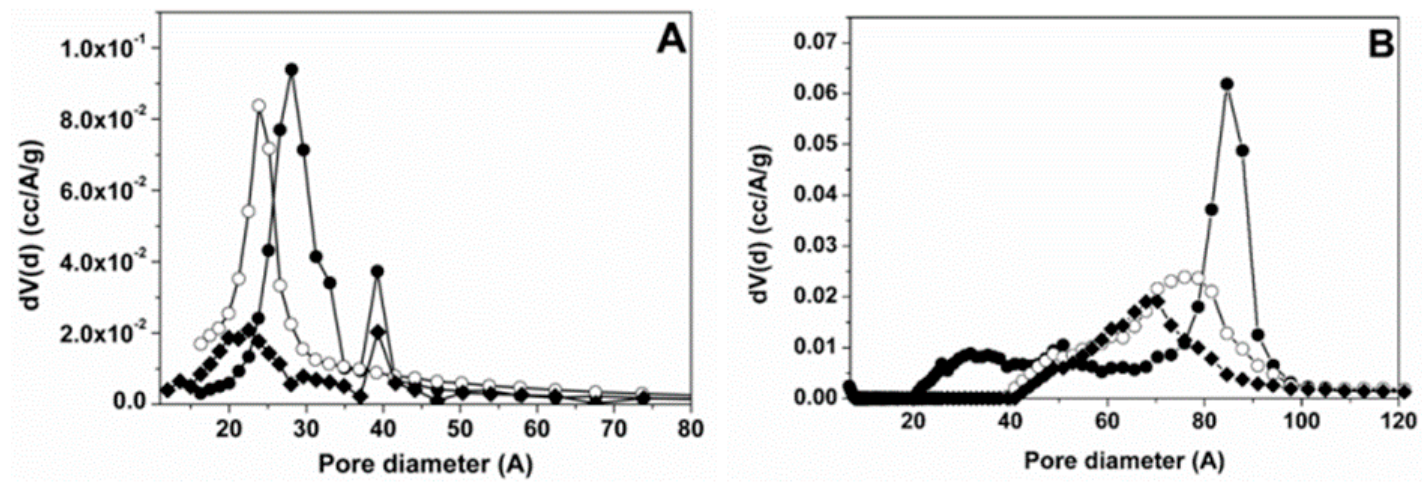

Figure 3. Pore-diameter distribution of MCM-41 (A, -•-), $\mathrm{NH}_{2}-\mathrm{MCM}-41(\mathbf{A},-\bigcirc-)$, TbDO3A-MCM-41

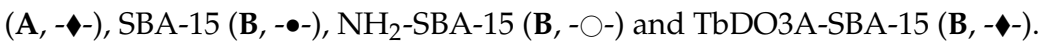

Table 1. Textural properties of all the solids. The specific surface area (SSA) was estimated by BET method and the total pores volume and diameters were determined by Barret-Joyner-Halenda (BJH) approach (applied to the desorption branch), for MCM-41 derivative samples, and by Non Localized Density Functional Theory (NLDFT) method for SBA-15 and functionalized systems.

\begin{tabular}{cccc}
\hline & Specific Surface Area $\left(\mathbf{m}^{\mathbf{2}} \mathbf{g}^{-\mathbf{1}}\right)$ & Pores Volume $\left(\mathbf{c c g}^{-1}\right)$ & Pores Diameter $(\mathbf{n m})$ \\
\hline MCM-41 & 905 & 1.90 & 2.8 \\
NH $_{2}$-MCM-41 & 880 & 1.42 & 2.4 \\
TbDO3A-MCM-41 & 410 & 0.77 & 2.3 \\
SBA-15 & 820 & 1.19 & 8.5 \\
NH $_{2}$-SBA-15 & 524 & 0.88 & 7.6 \\
TbDO3A-SBA-15 & 354 & 0.61 & 6.5 \\
\hline
\end{tabular}

TbDO3A-MCM-41 showed a significant decrease (almost 50\%) of both specific surface area and pores volume (Figure 3A, Table 1 ). In agreement with parent systems $[25,30,31]$ it can be inferred that the complexes are mainly anchored on the external surface of MCM-41 (Figure 1) and part of them are in close proximity to the pores entrance, promoting a partial blocking of the channels. Also, SBA-15 and the functionalized systems showed type "IV" isotherms but with an H1 hysteresis loop, representative of mesoporous cylindrical or rod-like pores (Supplementary Figure S5) [30]. As shown in Table 1 and Figure 3B, the functionalization of SBA-15 with amino groups led to a decrease of both SSA and pores size, and a further restriction of the pores diameter was observed after conjugation of $\mathrm{Tb}$ (III)-DO3A chelates and PEG molecules (from 7.6 to $6.5 \mathrm{~nm}$ ). These data are in line with those already reported for similar systems suggesting that an important fraction of $\mathrm{Tb}(\mathrm{III})$ complexes are confined inside the channels.

It has already been shown for Gd(III)-complexes anchored onto MCM-41 and SBA-15 MSNs that the different localization of the chelates greatly influences the relaxometric properties of the materials [30]. Thus, the CEST properties of TbDO3A-MCM-41 and TbDO3A-SBA-15 were investigated in order to obtain further insights into the physical properties of such nanomaterials, and especially to evaluate the influence of the reduced water diffusion into the pores on the CEST effect.

Although the particle dispersion and stability were improved by the presence of the PEG chains, the quite large amount of MSNs used $(20 \mathrm{mg} / \mathrm{mL})$ required the addition of $2 \mathrm{mg} / \mathrm{mL}$ of xanthan 
gum to favor the stability over time of the suspension and thus the accurate CEST measurement. DLS analysis measured at $298 \mathrm{~K}$ in PBS buffer evidenced the presence of micrometric aggregates for both the functionalized materials with a heterogeneous distribution of the particles size mainly evident for the pegylated TbDO3A-SBA-15 suspension (Supplementary Figure S6).

The CEST properties of TbDO3A-MCM-41 and TbDO3A-SBA-15 were evaluated at 7.1 T, $21^{\circ} \mathrm{C}$, pH 7 by acquiring Z-spectra on a Bruker $300 \mathrm{MHz}$ spectrometer equipped with a micro-imaging probe. The RARE (rapid acquisition with refocused echoes) sequence, typically employed for CEST MR imaging, was preceded by the pre-saturation scheme that consists in a continuous rectangular block pulse ( $\mathrm{B}_{1}$ in the range $12-42 \mu \mathrm{T}$, irradiation time $\left.2 \mathrm{~s}\right)$. The ST\%- and Z-spectra of both Tb-MSNs and the control silica (without anchored complexes) with $\mathrm{B}_{1}=24 \mu \mathrm{T}$ are shown in Figure $4 \mathrm{~A}, \mathrm{~B}$ and Supplementary Figure S7, respectively. ST\%- and Z-spectra at the other $\mathrm{B}_{1}$ values are reported in Supplementary Figure S8.
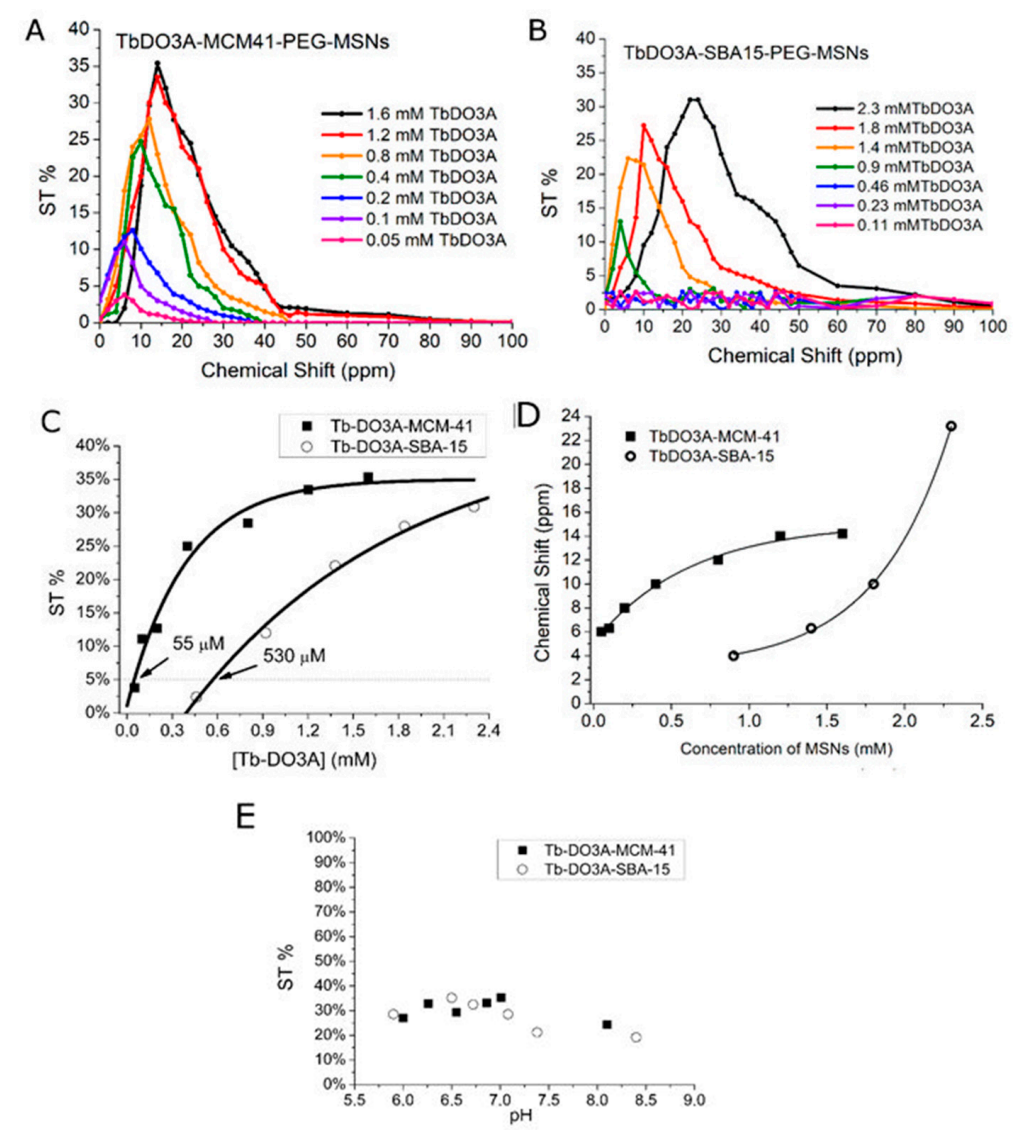

Figure 4. ST\% of (A) TbDO3A-MCM-41 and of (B) TbDO3A-SBA-15. (C) ST\% of variable concentrations of TbDO3A-MCM-41 (--) and TbDO3A-SBA-15 (-○-) MSNs. (D) Chemical shift of variable concentrations of TbDO3A-MCM-41 (-m-) and TbDO3A-SBA-15 (-○-) MSNs. (E) ST\% of variable pH values of TbDO3A-MCM-41 (-ם-) and TbDO3A-SBA-15 (-○-) MSNs.

It is well known that saturation efficiency ( $\mathrm{ST} \%$ ) increases by enhancing the applied $\mathrm{B}_{1}$ presaturation fields [39]. However, the most important limitation is the occurrence of a high tissue energy deposition (i.e., high specific absorption rate, SAR) when strong irradiation powers are employed. This hampers the use of high $B_{1}$ value for in vivo applications of CEST methodology [40]. The $B_{1}$ value of $24 \mu \mathrm{T}$ has been largely used in preclinical CEST studies by using PARACEST agents and nanosystems [39,41-43]. For this reason, we choose to use this irradiation power.

In the case of non-functionalized MSNs, no CEST effect is detectable, given the close proximity of the chemical shift values of water and hydroxyl protons in the absence of a paramagnetic center (data not shown). Conversely, when TbDO3A complexes are anchored to the silica surface, a largely shifted 
CEST signal is present for both materials. The CEST peaks appear broader at higher concentrations of MSNs, for the presence of micrometric aggregates of the nanoparticles, as suggested by DLS, and the $T_{2}$ shortening. The detection threshold for TbDO3A-MCM-41 and TbDO3A-SBA-15 was assessed by progressive dilution of silica suspensions in saline phosphate buffer (PBS) solution (Figure 4C).

As shown in Figure 4C, for TbDO3A-MCM-41 the ST\% is higher than 5\% (considered as threshold for the visualization) up to a silica concentration of $0.7 \mathrm{mg} / \mathrm{mL}$, that corresponds to a $\mathrm{Tb}$ (III) concentration of $55 \pm 5 \mu \mathrm{M}$. These results are in line with those recently reported for the analogue MSN system without PEG chain, thus showing that PEG does not influence CEST effect. Differently, for TbDO3A-SBA-15 the $\mathrm{ST} \%$ is higher than $5 \%$ up to a silica concentration of $2.3 \mathrm{mg} / \mathrm{mL}$ that corresponds to a $\mathrm{Tb}$ (III) concentration of $530 \pm 10 \mu \mathrm{M}$. Therefore, the latter system requires ten times higher concentration to be detected by CEST-MRI.

As shown in Figure 4D, the chemical shift of MSNs changes with the concentration of the nanoparticles. However, the chemical shift of TbDO3A-SBA-15 MSNs increases much more than in the case of TbDO3A-MCM-41 MSNs probably as a consequence of the presence of micrometric aggregates of the SBA-15 nanoparticles.

Finally, the $\mathrm{pH}$ dependences of CEST signals for both materials were also assessed showing that the ST\% effect slightly changes in the $6.0-8.5 \mathrm{pH}$ range (Figure 4E). A possible explanation of the slight reduction of the $\mathrm{ST} \%$ effect at higher $\mathrm{pH}$ values can be the partial deprotonation of the silanol groups. Samples at $\mathrm{pH}<6$ were not investigated in order to avoid substantial alterations of the silica surface and thus to change the interaction between the silanol groups and the LnDO3A complexes.

Furthermore, both systems clearly act as $T_{2}$ contrast agents because of the presence of Tb-complex. $T_{2 \mathrm{w}}$ and ST\%-maps of TbDO3A-MCM-41 and TbDO3A-SBA-15 at variable concentration or $\mathrm{pH}$ are reported in Figure 5. $T_{2}$ measurements of specimens are reported in Figure S9. The $T_{2}$ value of a suspension of TbDO3A-MCM-41 is shorter than the one of TbDO3A-SBA-15 (i.e., $45 \mathrm{vs.} 180 \mathrm{ms,}$ respectively. In both cases for $1 \mathrm{mM}$ of Tb-DO3A complex). The $r_{2}$ values of TbDO3A-MCM-41 and TbDO3A-SBA-15 are 21.7 and $5 \mathrm{mM}^{-1} \mathrm{~s}^{-1}$, respectively.

A

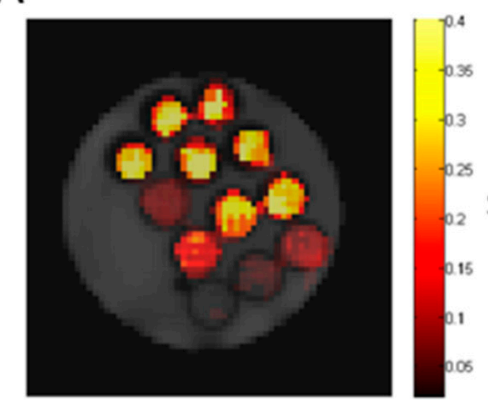

C

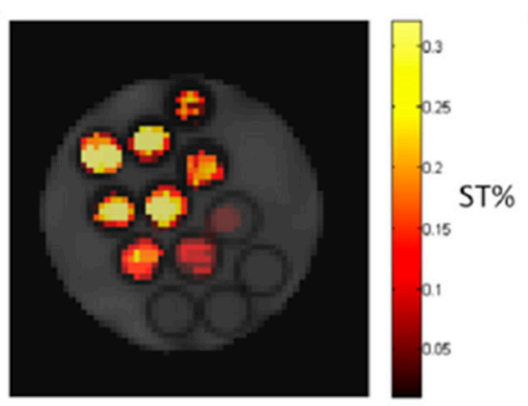

B

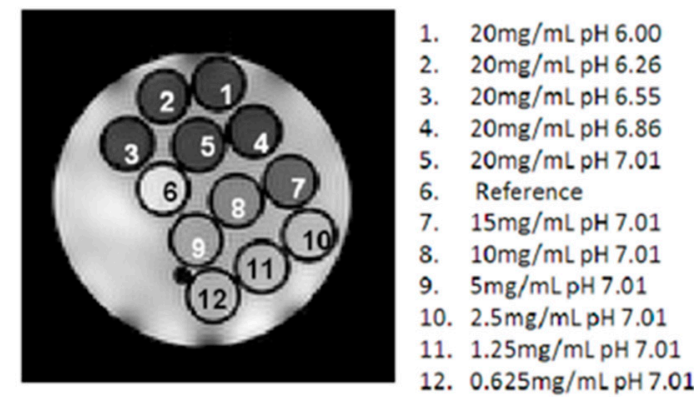

D

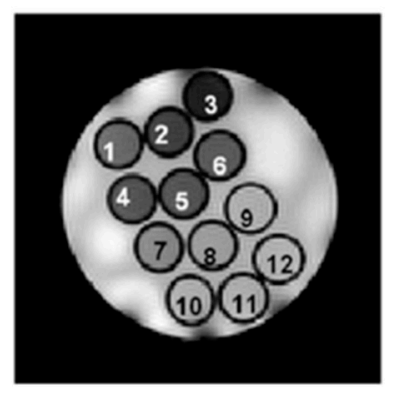

$10 \mathrm{mg} / \mathrm{mL} \mathrm{pH} 5.90$ $10 \mathrm{mg} / \mathrm{mL} \mathrm{pH} 6.50$ $10 \mathrm{mg} / \mathrm{mL}$ pH 6.72 $10 \mathrm{mg} / \mathrm{mL}$ pH 7.08 $10 \mathrm{mg} / \mathrm{mL} \mathrm{pH} 7.38$ $10 \mathrm{mg} / \mathrm{mL}$ pH 8.40 $8 \mathrm{mg} / \mathrm{mL}$ pH 7.08 $6 \mathrm{mg} / \mathrm{mL} \mathrm{pH} 7.08$ 9. $4 \mathrm{mg} / \mathrm{mL}$ pH 7.08 10. $2 \mathrm{mg} / \mathrm{mL}$ pH 7.08 11. $1 \mathrm{mg} / \mathrm{mL}$ pH 7.08 12. $0.5 \mathrm{mg} / \mathrm{mL}$ pH 7.08

Figure 5. $T_{2 \mathrm{w}}(\mathbf{A}, \mathbf{B})$ and ST\% maps (C,D) of TbDO3A-MCM-41 (A,C) and TbDO3A-SBA-15 (B,D) MSNs at variable concentration or $\mathrm{pH}$ values. 


\section{Discussion}

Some years ago, we reported that LnDO3A-MCM-41 MSNs can be efficient CEST-MRI contrast agents [25]. In particular, the paramagnetic metal of LnDO3A complexes anchored on the silica surface can interact, in a revertible way, with multiple-OH moieties of silanol groups on the particle surface. This interaction generates a very sensitive CEST system, much more than the classical monomeric PARACEST agents (e.g., LnHPDO3A complexes), but with a chemical shift closer to water resonance.

Different lanthanides (i.e., $\mathrm{Eu}, \mathrm{Tm}, \mathrm{Tb}, \mathrm{Gd}$ ) were investigated and the Tb-complex was demonstrated to be the best one, as a result of the larger chemical shift and excellent sensitivity down to the $\mathrm{mM}$ range. Starting from those results, herein we compared two different kind of MSNs, i.e., MCM-41 and SBA-15 functionalized with a Tb(III)-DO3A derivative. The synthesis followed experimental procedures previously reported and the anchoring process was monitored by IR spectroscopy and thermogravimetric analysis. The data suggested that a large fraction of the $\mathrm{NH}_{2}$ groups exposed on the silica surface were involved in the reaction with the $\mathrm{Tb}(\mathrm{III})$-complex and the functionalized PEG molecules. The $\mathrm{N}_{2}$ physisorption data clearly indicated that the location of the complexes is different in the two solids. In case of MCM-41, characterized by pores with $2.8 \mathrm{~nm}$ diameter, the $\mathrm{Tb}(\mathrm{III})$-chelates are distributed on the external surface or in the pores entrance as testified by the strong reduction of the pore volumes. In contrast, the complexes are located mainly inside the channels of the SBA-15, as it is composed by large pores (diameter of $8.5 \mathrm{~nm}$ ).

In this kind of CEST-MRI nanoprobes, the CEST effect arises because of the multiple interaction between the silanol groups in proximity to the anchoring site and the LnDO3A metal center. In addition, another hypothesis of the large CEST efficiency might be related to an increased prototropic exchange rate [25]. However, in both cases, the difficulty of the water molecules to reach the paramagnetic centers inside the silica pores strongly hampers the efficiency of such mechanisms. For this reason, the CEST efficiency of TbDO3A-MCM-41 is much higher (one order of magnitude) than the one displayed by TbDO3A-SBA-15. In particular, a ST $=5 \%$ is reached when TbDO3A-MCM-41 have silica concentration of $0.7 \mathrm{mg} / \mathrm{mL}$ (corresponding to $55 \pm 5 \mu \mathrm{M}$ of $\mathrm{Tb}$ ). On the contrary, for TbDO3A-SBA-15, ST $=5 \%$ is reached at a silica concentration of $2.3 \mathrm{mg} / \mathrm{mL}$ (corresponding to $530 \pm 10 \mu \mathrm{M}$ of $\mathrm{Tb}$ ).

The ST\% for a suspension of MSNs with $1 \mathrm{mM}$ of $\mathrm{Tb}-\mathrm{DO} 3 \mathrm{~A}$ complex is $32 \%$ and $15 \%$, for TbDO3A-MCM-41 and TbDO3A-SBA-15 MSNs, respectively.

These results indicate that MCM-41 MSNs are more efficient than SBA-15 MSNs because most of the $\mathrm{Tb}$-complexes are in the external surface of silica nanoparticles, hence water can easily interact with them.

In contrast, in the case of SBA-15 MSNs, the Tb-complexes are mainly located inside the pores where the water diffusion is hindered and, therefore, they are in part silent in terms of CEST effect.

\section{Conclusions}

This work shows how physico-chemical properties of the nanosystems play a pivotal role in generating the CEST effect. Hence, much attention has to be devoted to the properties of the MSNs, which are not only a carrier of the paramagnetic complexes, but strongly contribute in modulating the ST effect.

This is important for understanding the determinants of the efficiency of such systems as MRI contrast agents. Furthermore, besides the use of this information for generating highly sensitive and efficient MRI contrast agents, CEST analysis was demonstrated to be a suitable and easy tool for investigating the water diffusion in silica channels, thus providing insights into physico-chemical properties of this kind of nanosystems.

Supplementary Materials: The following are available online at http://www.mdpi.com/2312-7481/6/3/38/s1, Figure S1: TEM images; Figures S2 and S3: Thermogravimetric analysis; Figures S4 and S5: $\mathrm{N}_{2}$ adsorption/ desorption isotherms; Figure S6: DLS analysis; Figures S7 and S8: Additional Z- and ST-spectra. Figure S9: $T_{2}$ measurements 
Author Contributions: Conceptualization, F.C., G.F., and L.T.; Methodology, F.C., G.F., M.M.-Ú., and L.T.; Investigation, F.C., G.F., and M.M.-Ú.; Resources, L.T.; Data Curation, F.C. and G.F.; Writing-Original Draft Preparation, F.C., G.F., and L.T.; Writing-Review \& Editing, F.C., G.F., and L.T.; Supervision, F.C., G.F., and L.T.; Funding Acquisition, L.T. All authors have read and agreed to the published version of the manuscript.

Funding: This research was supported by MIUR (PRIN 2012; project 2012SK7ASN_002) and Compagnia di San Paolo (CSP-2014 THERASIL Project, F.C., L.T.).

Acknowledgments: This study was performed under the auspices of COST Action TD1004.

Conflicts of Interest: The authors declare no conflict of interest.

\section{References}

1. Vivero-Escoto, J.L.; Huxford-Phillips, R.C.; Lin, W. Silica-based nanoprobes for biomedical imaging and theranostic applications. Chem. Soc. Rev. 2012, 41, 2673-2685. [CrossRef] [PubMed]

2. Chen, Y.; Chen, H.; Shi, J. In Vivo Bio-Safety Evaluations and Diagnostic/Therapeutic Applications of Chemically Designed Mesoporous Silica Nanoparticles. Adv. Mater. 2013, 25, 3144-3176. [CrossRef] [PubMed]

3. Colilla, M.; González, B.; Vallet-Regí, M. Mesoporous silicananoparticles for the design of smart delivery nanodevices. Biomater. Sci. 2013, 1, 114-134. [CrossRef] [PubMed]

4. Rosenholm, J.M.; Sahlgren, C.; Lindén, M. Towards multifunctional, targeted drug delivery systems using mesoporous silicananoparticles - opportunities \& challenges. Nanoscale 2010, 2, 1870-1883.

5. Nakamura, T.; Sugihara, F.; Matsushita, H.; Yoshioka, Y.; Mizukami, S.; Kikuchi, K. Mesoporous silica nanoparticles for 19F magnetic resonance imaging, fluorescence imaging, and drug delivery. Chem. Sci. 2015, 6, 1986-1990. [CrossRef]

6. Zhang, Q.; Wang, X.; Li, P.-Z.; Nguyen, K.T.; Wang, X.-J.; Luo, Z.; Zhang, H.; Tan, N.S.; Zhao, Y. Biocompatible, Uniform, and Redispersible Mesoporous Silica Nanoparticles for Cancer-Targeted Drug Delivery In Vivo. Adv. Funct. Mater. 2014, 24, 2450-2461. [CrossRef]

7. Lee, J.E.; Lee, N.; Kim, H.; Kim, J.; Choi, S.H.; Kim, J.H.; Kim, T.; Song, I.C.; Park, S.P.; Moon, W.K.; et al. Uniform mesoporous dye-doped silica nanoparticles decorated with multiple magnetite nanocrystals for simultaneous enhanced magnetic resonance imaging, fluorescence imaging, and drug delivery. J. Am. Chem. Soc. 2010, 132, 552-557. [CrossRef]

8. Carniato, F.; Muñoz-Úbeda, M.; Tei, L.; Botta, M. Selective functionalization of mesoporous silica nanoparticles with ibuprofen and Gd(III) chelates: A new probe for potential theranostic applications. Dalton Trans. 2015, 44, 17927-17931. [CrossRef]

9. Carniato, F.; Tei, L.; Arrais, A.; Marchese, L.; Botta, M. Selective Anchoring of Gd ${ }^{\mathrm{III}}$ Chelates on the External Surface of Organo-Modified Mesoporous Silica Nanoparticles: A New Chemical Strategy To Enhance Relaxivity. Chem. Eur. J. 2013, 19, 1421-1428. [CrossRef]

10. Carniato, F.; Tei, L.; Botta, M. Gd-Based Mesoporous Silica Nanoparticles as MRI Probes. Eur. J. Inorg. Chem. 2018, 46, 4936-4954. [CrossRef]

11. Ward, K.M.; Aletras, A.H.; Balaban, R.S. A new class of contrast agents for MRI based on proton chemical exchange dependent saturation transfer (CEST). J. Magn. Reson. 2000, 143, 79-87. [CrossRef] [PubMed]

12. Van Zijl, P.C.; Yadav, N.N. Chemical exchange saturation transfer (CEST): What is in a name and what isn't? Magn. Reson. Med. 2011, 65, 927-948. [CrossRef] [PubMed]

13. Sherry, A.D.; Woods, M. Chemical exchange saturation transfer contrast agents for magnetic resonance imaging. Annu. Rev. Biomed. Eng. 2008, 10, 391-411. [CrossRef] [PubMed]

14. Yadav, N.N.; Jones, C.K.; Hua, J.; Xu, J.; van Zijl, P.C. Imaging of Endogenous Exchangeable Proton Signals in the Human Brain Using Frequency Labeled Exchange (FLEX) Transfer Imaging. Magn. Reson. Med. 2013, 69, 966-973. [CrossRef] [PubMed]

15. Walker-Samuel, S.; Ramasawmy, R.; Torrealdea, F.; Rega, M.; Rajkumar, V.; Johnson, S.P.; Richardson, S.; Gonçalves, M.; Parkes, H.G.; Arstad, E. In vivo imaging of glucose uptake and metabolism in tumors. Nat. Med. 2013, 19, 1067-1072. [CrossRef]

16. Soesbe, T.C.; Wu, Y.; Sherry, A.D. Advantages of paramagnetic CEST complexes having slow-to-intermediate water exchange properties as responsive MRI agents. NMR Biomed. 2013, 26, 829-838. [CrossRef] 
17. Ferrauto, G.; di Gregorio, E.; Castelli, D.D.; Aime, S. CEST-MRI studies of cells loaded with lanthanide shift reagents. Magn. Reson. Med. 2018, 80, 1626-1637. [CrossRef]

18. Hingorani, D.V.; Bernstein, A.S.; Pagel, M.D. A review of responsive MRI contrast agents: 2005-2014. Contrast Media Mol. Imaging 2015, 10, 245-265. [CrossRef]

19. Ferrauto, G.; di Gregorio, E.; Auboiroux, V.; Petit, M.; Berger, F.; Aime, S.; Lahrech, H. CEST-MRI for glioma pH quantification in mouse model: Validation by immunohistochemistry. NMR Biomed. 2018, 31, e4005. [CrossRef]

20. De Leon-Rodriguez, L.M.; Lubag, A.J.; Malloy, C.R.; Martinez, G.V.; Gillies, R.J.; Sherry, A.D. Responsive MRI Agents for Sensing Metabolism in Vivo. Acc. Chem. Res. 2009, 42, 948-957. [CrossRef]

21. Ferrauto, G.; Castelli, D.D.; di Gregorio, E.; Langereis, S.; Burdinski, D.; Grüll, H.; Terreno, E.; Aime, S. Lanthanide-loaded erythrocytes as highly sensitive chemical exchange saturation transfer MRI contrast agents. J. Am. Chem. Soc. 2014, 136, 638-641. [CrossRef]

22. Ferrauto, G.; Delli Castelli, D.; Di Gregorio, E.; Terreno, E.; Aime, S. LipoCEST and cellCEST imaging agents: Opportunities and challenges. WIREs Nanomed. Nanobiotechnol. 2016, 8, 602-618. [CrossRef] [PubMed]

23. Wu, Y.; Evbuomwan, M.; Melendez, M.; Opina, A.; Sherry, A.D. Advantages of macromolecular to nanosized chemical-exchange saturation transfer agents for MRI applications. Future Med. Chem. 2010, 2, 351-366. [CrossRef]

24. McMahon, M.T.; Chan, K.W. Developing MR probes for molecular imaging. Adv. Cancer Res. 2014, 124, 297-327. [PubMed]

25. Ferrauto, G.; Carniato, F.; Tei, L.; Hu, H.; Aime, S.; Botta, M. MRI nanoprobes based on chemical exchange saturation transfer: $\mathrm{Ln}^{\mathrm{III}}$ chelates anchored on the surface of mesoporous silica nanoparticles. Nanoscale 2014, 6, 9604-9607. [CrossRef] [PubMed]

26. Ferrauto, G.; di Gregorio, E.; Baroni, S.; Aime, S. Frequency-encoded MRI-CEST agents based on paramagnetic liposomes/RBC aggregates. Nano Lett. 2014, 10, 6857-6862. [CrossRef]

27. Debroye, E.; Eliseeva, S.V.; Laurent, S.; Elst, L.V.; Muller, R.; Parac-Vogt, T.N. Micellar self-assemblies of gadolinium(III)/europium(III) amphiphilic complexes as model contrast agents for bimodal imaging. Dalton Trans. 2014, 43, 3589-3600. [CrossRef]

28. Zhao, J.M.; Har-el, Y.E.; McMahon, M.T.; Zhou, J.; Sherry, A.D.; Sgouros, G.; Bulte, J.W.; van Zijl, P.C. Size-Induced Enhancement of Chemical Exchange Saturation Transfer (CEST) Contrast in Liposomes. J. Am. Chem. Soc. 2008, 130, 5178-5184. [CrossRef]

29. Tripepi, M.; Ferrauto, G.; Bennardi, P.O.; Aime, S.; Castelli, D.D. Multilamellar LipoCEST Agents Obtained from Osmotic Shrinkage of Paramagnetically Loaded Giant Unilamellar Vescicles (GUVs). Angew. Chem. Int. Ed. 2020, 132, 2299-2303. [CrossRef]

30. Carniato, F.; Tei, L.; Dastrù, W.; Marchese, L.; Botta, M. Relaxivity modulation in Gd-functionalised mesoporous silicas. Chem. Commun. 2009, 10, 1246-1248. [CrossRef]

31. Carniato, F.; Tei, L.; Cossi, M.; Marchese, L.; Botta, M. A Chemical Strategy for the Relaxivity Enhancement of $\mathrm{Gd}^{\mathrm{III}}$ Chelates Anchored on Mesoporous Silica Nanoparticles. Chem. Eur. J. 2010, 16, 10727-10734. [CrossRef] [PubMed]

32. Davis, J.J.; Huang, W.-Y.; Davies, G.-L. Location-tuned relaxivity in Gd-doped mesoporous silica nanoparticles. J. Mater. Chem. 2012, 22, 22848-22850. [CrossRef] [PubMed]

33. Faraone, A.; Liu, L.; Mou, C.-Y.; Shih, P.-C.; Copley, J.R.D.; Chen, S.-H. Translational and rotational dynamics of water in mesoporous silica materials: MCM-41-S and MCM-48-S. J. Chem. Phys. 2003, 119, 3963-3971. [CrossRef]

34. Takayama, Y.; Yoshiura, T.; Nishie, A.; Nakayama, T.; Hatakenaka, M.; Kato, N.; Yoshise, S.; Keupp, J.; Burdinski, D.; Honda, H. Ytterbium-based PARACEST agent: Feasibility of CEST imaging on a clinical MR scanner. Magn. Res. Med. Sci. 2012, 11, 35-41. [CrossRef]

35. Zhao, D.; Huo, Q.; Feng, J.; Chmelka, B.F.; Stucky, G.D. onionic Triblock and Star Diblock Copolymer and Oligomeric Surfactant Syntheses of Highly Ordered, Hydrothermally Stable, Mesoporous Silica Structures. J. Am. Chem. Soc. 1998, 120, 6024-6036. [CrossRef]

36. Terreno, E.; Stancanello, J.; Longo, D.; Castelli, D.D.; Milone, L.; Maarten, B.K.; Uggeri, F.; Aime, S. Methods for an improved detection of the MRI-CEST effect. CMMI 2009, 4, 237-247. [CrossRef] 
37. Zecchina, A.; Bordiga, S.; Spoto, G.; Marchese, L.; Petrini, G.; Leofanti, G.; Padovan, M. Silicalite characterization. 2. IR spectroscopy of the interaction of carbon monoxide with internal and external hydroxyl groups. J. Phys. Chem. 1992, 96, 4991-4997. [CrossRef]

38. Thommes, M.; Köhn, R.; Fröba, M. Sorption and pore condensation behavior of pure fluids in mesoporous MCM-48 silica, MCM-41 silica, SBA-15 silica and controlled-pore glass at temperatures above and below the bulk triple point. Appl. Surf. Sci. 2002, 196, 239-249. [CrossRef]

39. Ferrauto, G.; Aime, S.; McMahon, M.T.; Morrow, J.R.; Snyder, E.M.; Li, A.; Bartha, R. Chemical Exchange Saturation Transfer (CEST) Contrast Agents. Chapter 3. In Contrast Agents for MRI: Experimental Methods; Pierre, V., Allen, M., Eds.; Royal Society of Chemistry Publishing: Cambridge, UK, 2017.

40. Burns, P.J.; Cox, J.M.; Morrow, J.R. Imidazole-Appended Macrocyclic Complexes of Fe(II), Co(II), and Ni(II) as ParaCEST Agents. Inorg. Chem. 2017, 56, 4545-4554. [CrossRef]

41. Ali, M.M.; Woods, E.M.; Suh, E.H.; Kovacs, Z.; Tircso, G.; Zhao, P.; Kodibagkar, V.D.; Sherry, A.D. Albumin-binding PARACEST agents. J. Biol. Inorg. Chem. 2017, 12, 855-865. [CrossRef]

42. Srivastava, K.; Ferrauto, G.; Harris, S.H.; Longo, D.L.; Botta, M.; Aime, S.; Pierre, V.C. Complete on/off responsive ParaCEST MRI contrast agents for copper and zinc. Dalton Trans. 2018, 47, 11346-11357. [CrossRef] [PubMed]

43. Zaiss, M.; Angelowski, G.; Demetriou, E.; McMahon, M.T.; Golay, X.; Scheffler, K. QUESP and QUEST revisited-Fast and accurate quantitative CEST experiments. Magn. Res. Med. 2018, 79, 1708-1721. [CrossRef] [PubMed]

(C) 2020 by the authors. Licensee MDPI, Basel, Switzerland. This article is an open access article distributed under the terms and conditions of the Creative Commons Attribution (CC BY) license (http://creativecommons.org/licenses/by/4.0/). 